DOI: 10.33727/JRISS.2021.2.3:27-30

\title{
Aspects of cost analysis in semi-solid state processing
}

\author{
Adrian Constantin Tanasie ${ }^{\mathbf{1}}$, \\ ${ }^{I}$ WEST.RO SUPPORT SRL, Timisoara, Romania \\ E-mail:aditanasie74@gmail.com
}

\begin{abstract}
This paper pretexts the main data of economic processing in semi-solid State of pieces, to continuous and study thorougly returns of this new method, to obtwo parts with higher features and small prices comparable with classical methods. Its were presented, also, the processes technologies in semi-solid State and the aids of these.
\end{abstract}

Keywords: Semi-solid, costs, tixoformation, reotisation

\section{Introduction}

In modern technology, parts with increasingly diverse physical-mechanical characteristics are needed, and the metalworking industry has an increasing interest in obtaining parts in the most advantageous technical-economic conditions. Reducing production costs is therefore one of the main objectives in modern industry.

These requirements require that existing procedures be improved or the best technology found so that the resulting parts are as close to the finished part as possible, with minimal technological loss of material and energy and as few steps as possible. This will result in a lower cost price.

The cost price of die-finished parts can be reduced under the current conditions, in particular by obtaining parts with a finished shape and a very good surface quality that no longer requires machining on machine tools or manual sanding.

Therefore, semi-solid material processing is a new technology that can meet some of the needs of modern industry because it offers a number of advantages including: obtaining finished parts with complex geometry, reduced friction forces, which means lower energy costs as well as superior mechanical characteristics.

In recent years, a problem that is increasingly discussed by specialists is the reduction of environmental impact. Thus, by semi-solid processing, the energy economy can reach $30 \%$ as the semifinished products are partially melted without overheating.

\section{Semi-solid processing techniques for materials}

\subsection{Tixoformation}

The most well-known semi-solid processing technology for metals and metal alloys is thixoformation. For the first time David Spencer in 1971, a student, observed that their metals and alloys which are in semi-solid state and have a globalized structure, have time-dependant tyxotrophic properties $[2,3]$.

On the basis of these considerations, a new technology has been developed, i.e. semi-solid processing. Materials with thixotrophic properties can be processed by tixoturnating or tixomatritation. 
The expression tixo in the name of the procedure comes from the term tyxotrophy which was used by Peterfi (1927) to define the ownership of suspensions and solutions to gelatinise when at rest and to become fluid when agitated.

Tyxotrophic-behavior alloys in semi-solid state retain their own shape, but easily deform when a force is applied to them.

The semi-solid materials can also be easily cut and deformed as shown in Figure 1. More semi-solid alloys having a solid fraction of between 50 and $70 \%$ and are at rest self-supporting and can be handled as a solid (see Figure 1).
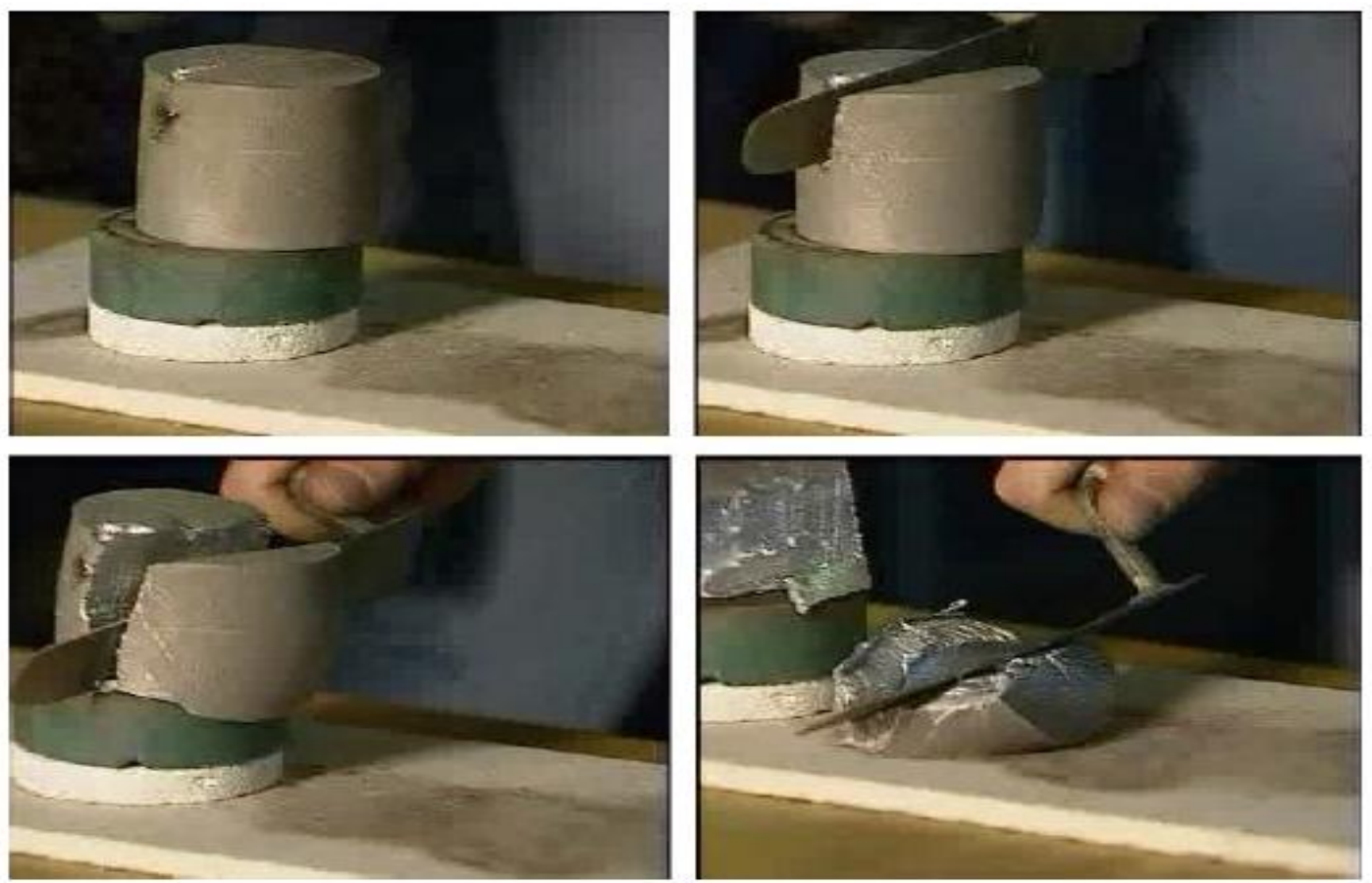

Figure 1 Semi-solid material [4]

The choice of part processing technology is in most cases determined by the material used,and in many cases parts of the same alloy can be obtained by different methods.

The solution chosen must ensure the best quality parts and a low cost price.

As shown in Figure 2 tixoformation requires average production costs and a sufficiently good quality.

So this technology meets the expectations of the metalworking industry, enabling quality parts to be obtained at lower prices.

\subsection{The resupply}

Another economic process of semi-solid processing of materials is reotinting. A variant of the process called NRC (new Rheocasting process) was developed by UBE Industries Ltd and combines squeeze process technology with a new method of obtaining semi-solid metal suspension. The process consists of injecting alloys in the semi-solid state at low pressure into the cavity of the metal shape and maintaining high pressure during solidification.

In the NRC process, the scooter is prepared in its own foundry. The globular structure is obtained by controlled cooling and not by electromagnetic agitation.

The cost of returned parts is about $20 \%$ lower than the cost of tixoforming.

Another DCRC processing technology (the direct cooling reoturnment process) was developed by BCAST at Brunel University to produce high quality magnesium alloy ingots and semi-finished 
products. Experimental results show that the ingots obtained by this process have a fine microstructure throughout the section and offer an excellent combination of mechanical and physical properties [6].

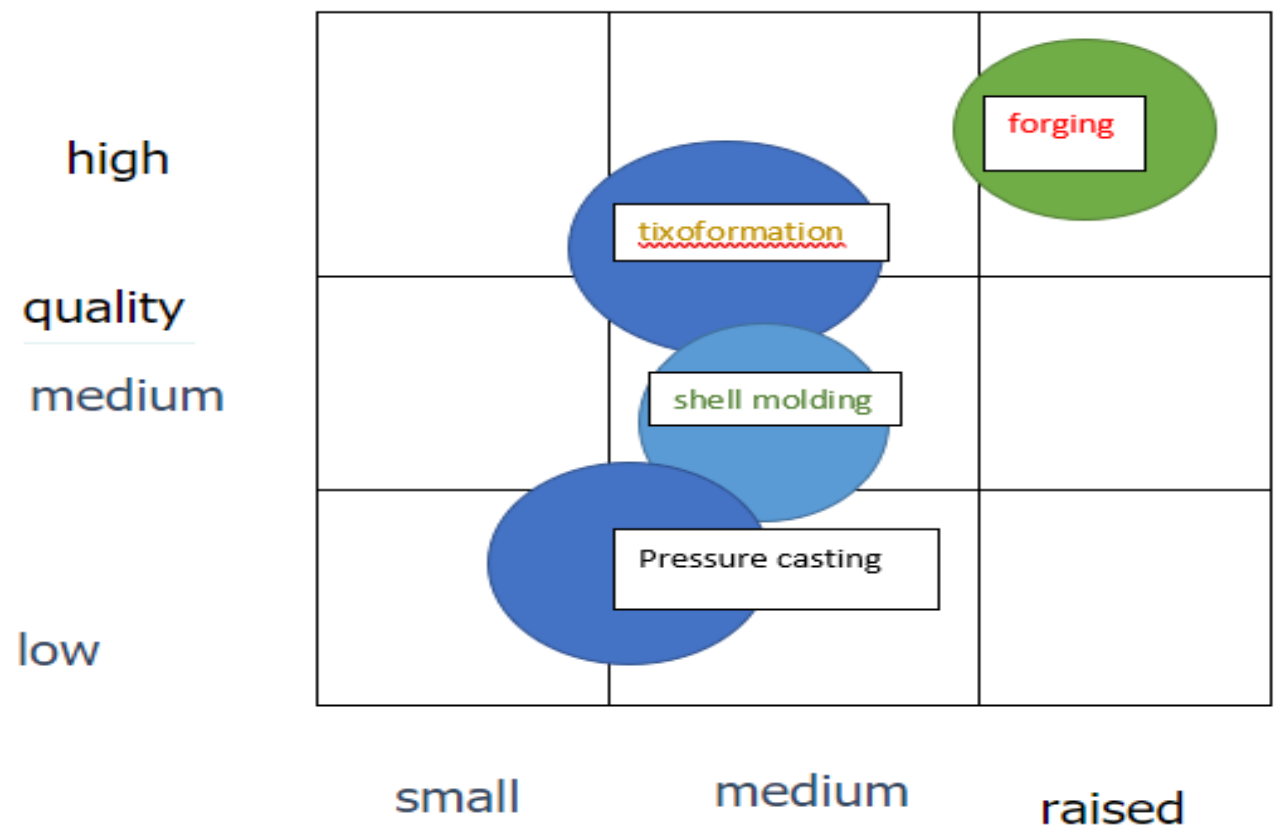

Figure 2 Change in quality and production costs of parts produced by different processes [5]

\section{Advantages of semi-solid processing}

Parts obtained by traditional casting (in forms of mixtures based on foundry sand) have high costs due to the multitude of processing operations.

The casting of semi-solid materials (SSM casting) provides manufacturers and usersof metal parts with a coger cost alternative and better quality parts compare do tradicional pressure casting methods.

These advantages are given by [6]:

- thermal fatigue and reduced wear of casting;

-the achievement of parts with reduced porosity caused by contraction, which is due to the coger temperatura of the semi-solid material compared to the liquid one;

- lower material temperature reduces mold termal cycles;

Increased casting speed on semi-solid material that has a higher viscosity than liquid processing, - viscosity control results in less turbulent casting which minimizes the emisión of gases, porosity, contraction of parts and other solidification defects;

Reduced work piece voltajes which are determined by the low forces required for semi-solid forging compared to the convencional method of forging solid metals;

- fine microstructures leading to better mechanical performance.

A case study of the costs of a segmented bolt and puma casing obtained by casting in sand compared to the casting of SSM was carried out by OTA Technology [6].

The study concluded that:

- for the segmented bolt (Fig.3) obtained by semi-solid processing, a 38\% reduction in total cost was achieved.

- for the pump case (Fig.4) cost reduction is $46 \%$ using SSM casting compared to sand casting, plus the metal shape has a longer lifetime resulting in a total increase of $54 \%$ saved percent. In addition, the disposal of lead-contaminated sandsfrom conventional OSH casting issignificantly reduced by contamination of the water by lead contained in the work piece. 


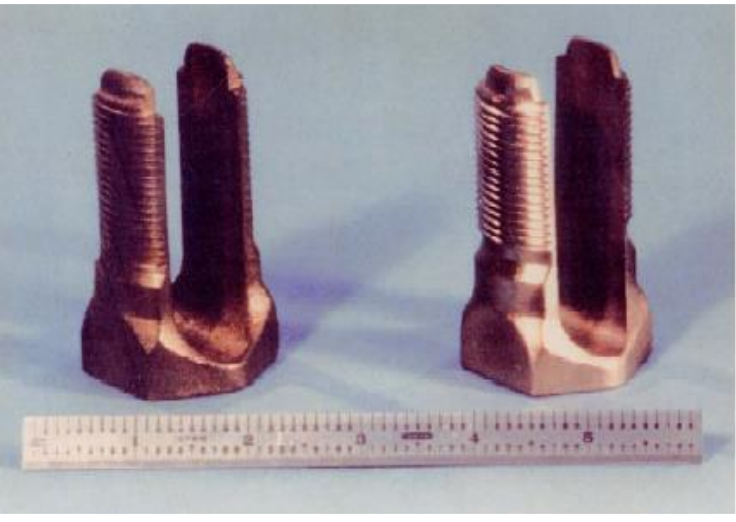

Figure 3 Segemontedbolt

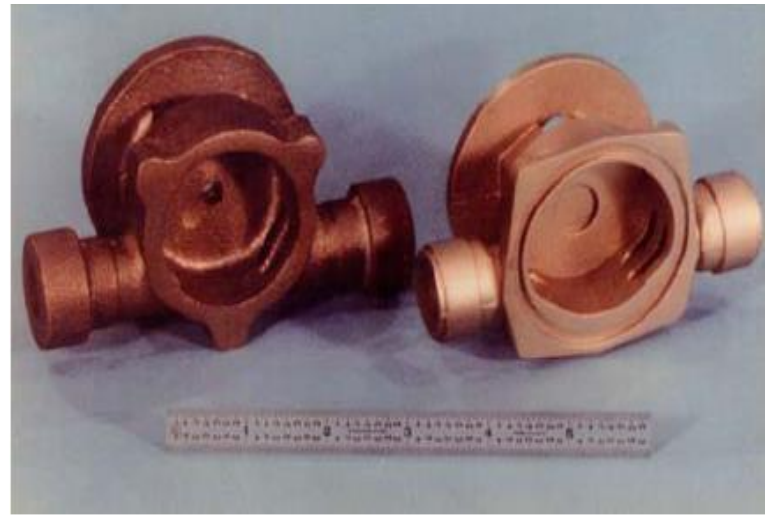

Figure 4 Pumphousing

\section{Conclusions}

SSM technology offers great potencial to reduce economic, energy and material costs. This technology also reduces the environmental impact of casting.

Semi-solid processing (due to the high viscosity of the thixotrotic behavior alloys) allows the laminar filling of the shape resulting in high integrity parts and superior mechanical properties, with a complex geometry, good surface quality and final shape, in a single production step.

As an alternative method to sand casting in castings by semi-solid processing, the environmental costs of depositing lead-contaminated sands are eliminated.

\section{References}

[1] Opris S., Carp H., the cement industry engineer's Manual, Technical Publishing, Bucharest, 1999.

[2] Biloni, H., Boettinger, J., Solification in physical method, edited by P. Haasen and R. W. Cahn, 1996, North Holland, Amsterdam, Vol. 1, pps 669-842.

[3] Flemings, M.C., semi-solid formation: The process and the path forward, Metallurgical Science and Technology, Vol. 18 (2), 2000.

[4] Baile Puig, T, Estudio de la Conformación de Components Aluminio-Silicio en Estado Shemisólido, Tesis doctoral, 2005, pp. 3-4

[5] ***www.polemetal.be.

[6] Zhang, S.M., fan, Z., Zhen, Z., direct Hill rheoocasting, material Science and technologies, Vol. 22, No. 12, 2006, pp. 1489-1498 